\title{
Product Market Regulation, Trend Inflation and Inflation Dynamics in the New Keynesian Phillips Curve
}

\author{
Laurence Bloch
}

23 June, 2009

\begin{abstract}
In this empirical paper, we take a close look at the impact of observed changes in the product market regulation, which raises barriers to entry and empediments to competition, on inflation dynamics since the early 1980s.

We use an enlarged new Keynesian Phillips curve (NKPC) allowing for entry of firms and for increasing competitive pressures with the number of firms and non zero trend inflation.

Using OECD indicators on product market regulations, characterized by persistent fluctuations of their underlying trends, and taking into account the non stationary properties of the inflation process, we investigate the empirical relevance of this NKPC for inflation dynamics in the US and France, with the additional assumption that shifts in monetary inflation target are related to changes in the product market regulation. We also assume $V A R$ expectations. The results point out that product market regulation is a good candidate as an exogenous structural source of the observed persistence in inflation for the last thirty years in both the US and France.

Keywords: Firm entry, Product market regulation, New Keynesian Phillips Curve, Trend inflation, Inflation dynamics, VAR.
\end{abstract}

JEL Classification: E31.

${ }^{*}$ CREST-INSEE, TJ310, 15, boulevard Gabriel Péri - 92245 Malakoff Cedex - France, tel:+33 (0)1 411760 34, Email: laurence.bloch@ensae.fr

${ }^{\dagger}$ The views expressed herein are those of the author and do not reflect the position of INSEE.

${ }^{\ddagger}$ We thank Guillaume Chevillon, Stéphane Grégoir, Guy Laroque, Hervé Le Bihan, and participants in the Macroeconometrics CREST Seminar and in the AFSE Congress 2008 for useful discussions.

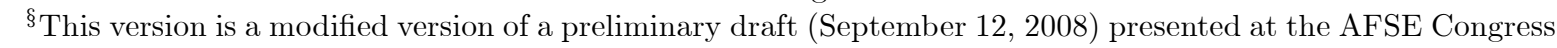
2008. 


\section{Introduction}

In this empirical paper we investigate in which extent the interaction between costs of entry on the product market which raises barriers to entry and empediments to competition and shifts in the long-run inflation target can account for lag dynamics and persistence in inflation since the early 1980s, using the New Keynesian Phillips Curve (NKPC) framework. We explicitly take in account the non-stationary properties of the inflation process but also those of the OECD indicator for product market regulation and costs of entry, characterized by persistent fluctuations of its underlying trend. Our theoretical departure point is a derived NKPC based on the standard Calvo (1983) optimal price setting with staggered prices, enlarged with a non zero steady state inflation, but also allowing entry of firms and increasing competitive pressures with the number of firms (see our companion paper Bloch (2009)).

In its basic form, the Calvo model leads to a purely forward-looking inflation specification relating inflation to expected inflation and fluctuations of real marginal costs of production. However, many empirical studies conclude that this version of the NKPC generates too little persistence to be consistent with empirical evidence. Consequentely, many authors improve the empirical fit of the NKPC by adding backward looking elements in the NKPC (the socalled "hybrid NKPC" including backward and forward elements). The justifications of the introduction of lags of inflation are of different types: a fraction of agents use adaptative instead of rational expectations (Roberts $(1997,2006)$, Ball (2000)); the fraction of firms which are not re-optimizing their prices follow an indexation rule on some general price inflation (Christiano et al. (2005)); some firms use rule-of-thumb pricing (Gali and Gerler (1999)); or agents are concerned with real wage instead of nominal wage (Phelps-Taylor) in a model of overlapping wage contracts (Fuhrer and Moore (1995)). These justifications have often been criticized because of their lack of convincing microeconomic foundation and are considered as ad-hoc.

Over the last years, a few authors have tried to find more founded explanations to persistence in macroeconomic variables, in particular inflation. Some authors departed from rational expectations and replaced it by learning mechanism. In that case agents do not know the structural parameters of the economy and use historical data to infer parameters: they learn over time, updating their beliefs. For example, in Milani (2007), using Bayesian method, the empirical results showed that learning can represent a potential single mechanism which can induce persistence without having to invoke indexation in the model. Schorfheide (2005) put forward learning of firms and households about monetary policy shifts in the target inflation rate, using learning rule to infer the current state of monetary policy and found that actual and expected inflation in the early 1980 can well be captured by the delayed response of the learning specification. Other authors used learning as a tool that can help in understanding some particular episodes of US inflation and monetary policy, which are often harder to explain under rational expectations. They focused on explanations why monetary policy shifts occur over time and put forward that the Central bank adjusts its target as it learns about the effectivness of its policy (Sargent (1999), Cogley and Sargent (2005), Primiceri (2006), and Sargent, Williams and Zha (2006)).

Recently, Cogley and Sbordone (2008) hypothesized that inflation persistence results mainly from variation in the long-run component of inflation. They argued that the apparent need for lagged inflation in the NKPC comes from neglecting the interaction between drift in trend 
inflation and non-linearities in a more exact version of the Calvo model taking into account a shifting steady state associated with a time-varying inflation trend.

The consequences of the assumption of non zero steady state inflation in the derivation of the new Keynesian Phillips curve (NKPC) based on Calvo price setting with staggered prices have already been explored on the theoretical side (King and Wolman (1996), Ascari (2004), Sahuc (2006) and Bakhshi and al. (2007)). The presence of a non zero steady state inflation alters the structure of the NKPC: the coefficients on past and future inflation as well as the slope of the NKPC then become functions of trend inflation. The NKPC then includes an additional forward-looking inflation variable with a complex structure. Furthermore, the slope of the NKPC decreases with trend inflation. This implication sits oddly to the stylized fact from the traditional Phillips curve literature and the conventional wisdom that Phillips curves are flatter at low inflation levels. To avoid these implications, Sahuc (2006) and Bakhshi and al. (2007) showed that the decrease of the slope with trend inflation can be weakened, even offset, through partial backward indexation of prices for firms, which do not reoptimize their prices in the Calvo price-setting, or through the frequency of price adjustment (Calvo price adjustment signal) becoming an inverse function of the trend inflation rate. On their side, Cogley and Sbordone (2008) were recently the first to provide an empirical estimation of the NKPC with a time varying inflation trend. Following Sbordone (2002, 2005) and Fanelli (2008), they estimated the model in two steps: first, estimating a Bayesian unrestricted VAR with drifting parameters and stochastic volatility; second, estimating the parameters of the pricing by exploiting cross-equations restrictions on the VAR parameters. Their estimations pointed out that the backward-looking indexation parameter concentrates on zero and that indexation appears to be unnecessary once drift in trend inflation is taken into account. The weight of future expectations is enhanced as trend inflation increases. However, Cogley and Sbordone estimations went on exhibiting a muted slope with increase in trend inflation, and thus an increasing slope since the beginning of the 1980s which is at odds with stylized facts. Moreover, they attributed fluctuations in the underlying inflation trend to shifts in monetary policy, but without testing this assertion. Previously, Kozicki and Tinsley (2002) had already put forward that shifts in "the anchor of long horizon inflation expectations" can be a potential source of lag dynamics in inflation. They estimated a multivariate $V A R$ with shifting endpoints where the only source of non stationarity directly derives from shifts in the steady state. Besides, Ireland (2007) tried to draw inferences about the behavior of the Fed's unobserved inflation target, looking closely at both assumptions: inflation target movements are deliberate policy response to exogenous supply-side shocks hitting the economy and movements in inflation target are purely random. He found that both interpretations are statistically indistinguishable and concluded that considerable uncertainty remains about the true source of shifts in the inflation target.

In this paper, building on the hypothesis of a non zero steady state inflation and time-varying inflation trend, we make the additional assumption that trend in inflation arises from shifts in the exogenous process of the product market regulation. Through this last assumption, we follow Ireland (2007) and the growing literature (already mentioned) assuming that the Central Bank learns from the structure of the economy. Our theoretical model is based on the NKPC with a non zero steady state inflation, but also allowing for entry of firms regulated by costs of entry and non fixed number of varieties, assuming a one to one identification between a producer, a differentiated good product and a firm. The elasticity of demand faced by firms and competitive 
pressures also increase with the number of varieties. This enlarged NKPC exhibits the following properties: 1) in the long run, real average marginal cost decreases with inflation, but this effect is enhanced in an economy where the cost of entry for firms is low; real average marginal cost also increases with the number of varieties; 2) in a context of decreasing trend inflation, the coefficients of the NKPC can be stabilized through the increase of competitive pressures and that of the elasticity of the demand faced by the firms, both implied by an increase in the tendency in the number of varieties. Thus, without referring to an increase in partial indexation or to an endogenous price rigidity, we reconcile theory with stylized facts (Bloch, 2009).

Bilbiie and al. (2007) have already put forward that net entry of firms induces an extra term linked to the fluctuations of the number of firms around the steady state and that this variable would take a part of the observed persistence in the dynamics of product price inflation in the NKPC. However, we argue that fluctuations of the number of firms, an a priori stationary variable, is empirically not a good candidate to match the observed persistence in inflation. Besides, increasing competition in the long run would contribute theoretically to flatten the slope of the traditional Phillips curve. However, empirical investigations focusing on the impact of globalization on the slope of the Phillips curve are rather inconclusive or provide contradictory conclusions $^{1}$ : Borio and Filardo (2007) empirically supported for many countries a "global slack" hypothesis since 1993, according to which the decline in the sensitivity of inflation to output gap can be explained by the fact that global measures od demand pressure have become the main driving force of inflation dynamics. Ihrig and al. (2007) questioned the global slack hypothesis, the latter not being robust to the specification of the measures of global slack. Finally, Ball (2006) allowed interaction of the output coefficient with trade in a traditional Phillips curve that was estimated for the US only and found only a modest effect. Sbordone (2008) put forward that globalization increases the elasticity of demand faced by firms, but decreases the elasticity of the desired mark-up; hence, globalization decreases the slope of the NKPC only for large enough increases in the number of good traded.

We investigate the empirical relevance of our derived NKPC for inflation dynamics with the additional assumption that shifts in monetary inflation target originate from product market regulation's ones. In the same vein as Cogley and Sbordone (2008) or Cogley and al. (2008) for the inflation process, we take also into account the stochastic trend in the number of varieties and estimate an empirical version of our enlarged NKPC assuming VAR expectations. Following Sbordone (2002, 2005), Fanelli (2008) and Cogley and Sbordone (2008) we estimate the model in two steps, first estimating an unrestricted $V A R$, and then estimating the NKPC by exploiting cross-equations restriction on the $V A R$ parameters. We restrict the empirical evidence to two countries: the US and France, the first one is representative of the anglo-saxon area, flexible and where large reforms in the product market regulation have already been conducted during the last thirty years, the second is representative of the euro area, less flexible and where changes in the product market regulation started ten years later, from the late 1980 and are still in progress. The OECD indicators on product market regulation are characterized by high persistence coming from their underlying trend.

On one hand, we address the issue of potential misspecification of the basic NKPC model in case of omitted variables by taking into account the entry of firms through the product market regulation variable. To our knowledge, the recent empirical papers (already mentioned)

\footnotetext{
${ }^{1}$ See also Mishkin $(2007,2008)$, Roberts (2006).
} 
on this topic (Batini and al.(2005), Borio and Filardo (2007), Ball (2006), Ihrig and al. (2007) and Sbordone (2008)) have focused on the impact of globalization and increased global market competition on inflation, rather than on the impact of product market regulation.

On the other hand, through the link between stochastic trend inflation and product market regulation (behaviour of the Central Bank), we generate an exogenous structural source of persistence and thus we address the question of the observed inflation persistence in a forward looking model of inflation. Our econometric results show that the introduction of the product market regulation variable takes a part of the observed persistence in inflation and lowers the estimate of the partial indexation and hence of the backward looking component of inflation. Moreover, changes in product market regulation have a greater impact in the long run on trend inflation in the US than in France.

This paper is organized as follows. The next section gives the derived NKPC, extended to the cases of trend inflation with entry of firms and increasing competitive pressures with the number of firms. Section 3 assesses the empirical relevance of empirical versions of this NKPC for inflation dynamics for the US and France and discusses the robustness of the results.

\section{The Model}

Our empirical investigation is based on a new Keynesian (NK) model allowing endogenous number of producers of goods. We assume exogenous entry costs and firms enter instantaneously in each period until all expected profit opportunities are exploited. Nominal rigidities are introduced in the form of staggered price setting by firms using the formalism due to Calvo (1983). The NKPC is then derived, under entry of firms and in addition with elasticity of demand and competitive pressures increasing with the number of firms; the log-linearization around the steady state takes into account the non zero steady state inflation (for more details, see Bloch (2009)).

\subsection{The enlarged NKPC with non zero steady state, entry of firms and in- creasing competitive pressure with number of firms}

Our objective is to offer a structural explanation of the observed inflation persistence, allowing fluctuations both in the inflation trend and in the costs of entry tendency. Hence we depart from the traditional derivation of the Calvo model which assumes constant steady state and approximation (by log-linearization) of the equilibrium conditions of the Calvo pricing model around the steady state.

Thus at each period $t$, each firm, new entrant or pre-existing firm, behaves in maximizing their expected sum of profits as if it has perfect information on steady state values of gross inflation rate $\Pi_{t}$, number of products $N_{t}$ and entry costs $f_{E_{t}}$ and as if these steady state values are fixed in the future to constant values, respectively $\bar{\Pi}_{t}, \bar{N}_{t}, \bar{f}_{E}$.

We assume that the Central Bank conducts monetary policy according to a generalized Taylor rule where the Central Bank increases the short term nominal interest rate whenever the inflation rate rises above its target $\bar{\Pi}_{t}$. Following Ireland (2007) the time-varying inflation target $\bar{\Pi}_{t}$ evolves according to the rule:

$$
\bar{\Pi}_{t}=\alpha_{1} \bar{f}_{E}+\alpha_{2}
$$


This addition to the Taylor rule allows the Central Bank to adjust its inflation target in response to exogenous shocks to product market regulation. On their side, when optimizing, firms and consumers do not know this target rule.

Allowing for time-varying stochastic trends in inflation and in number of varieties has a direct consequence: when approximating the non-linear equilibrium conditions of the model, we take the log-linear approximation, in each period $t$, around a steady state associated with time-varying trends $\bar{\Pi}_{t}$ and $\bar{N}_{t}$ respectively in inflation and in number of varieties.

Finally, contrary to some authors (see for example Sims and Zha (2006)) we do not treat the change from one equilibrium to another as probabilistic.

Hence, at each period $t$, the equilibrium inflation is defined by the following local approximation $^{2}$ :

$$
\begin{gathered}
\widehat{\pi}_{t}-\varrho \widehat{\pi}_{t-1}=-\varrho \widehat{g}_{t}^{\pi}+\gamma\left(\widehat{N}_{t-1}-\widehat{g}_{t}^{N}\right)-\frac{\gamma \varphi_{0 t}}{1-\alpha \bar{\Pi}_{t}^{(1-\varrho)\left(\theta\left(\bar{N}_{t}\right)-1\right)}} \widehat{N}_{t}+\varphi_{2 t} \varrho E_{t} \widehat{g}^{\pi}{ }_{t+1}-\gamma \varphi_{2 t}\left(\widehat{N}_{t}-E_{t} \widehat{g}_{t+1}\right)+\ldots \\
\ldots \frac{\gamma \varphi_{2 t} \varphi_{0 t}}{1-\alpha \bar{\Pi}_{t}^{(1-\varrho)\left(\theta\left(\bar{N}_{t}\right)-1\right)}} E_{t} \widehat{N}_{t+1}+\varphi_{4 t} \widehat{m c}_{t}+\varphi_{4 t}\left(\left(\gamma\left(\theta\left(\bar{N}_{t}\right)-1\right)-1\right)\left(\omega+\xi\left(\bar{N}_{t}\right)\right) \widehat{N}_{t}-\frac{\varphi_{4 t}}{(1-a)} \widehat{D}_{t}\right. \\
\ldots+\beta_{1 t} E_{t}\left(\widehat{\pi}_{t+1}-\varrho \widehat{\pi}_{t}\right)+\beta_{2 t} E_{t} \sum_{j=2}^{\infty} \varphi_{1}^{j}\left(\widehat{\pi}_{t+j}-\varrho \widehat{\pi}_{t+j-1}\right)+\beta_{3 t} E_{t} \sum_{j=0}^{\infty} \varphi_{1}^{j}\left(\widehat{q}_{t+j, t+j+1}+\widehat{g}_{t+1+j}\right)
\end{gathered}
$$

with the long run restriction between trend inflation $\bar{\Pi}_{t}$, trend number of firms $\bar{N}_{t}$ and trend real average marginal cost $\overline{m c}_{t}$ :

$$
\begin{gathered}
\left(1 / \overline{m c}_{t}\right)=\left[\left(\frac{1-\alpha \bar{\Pi}_{t}^{(1-\varrho)\left(\theta\left(\bar{N}_{t}\right)-1\right)}}{1-\alpha}\right)^{\frac{1-\theta\left(\bar{N}_{t}\right)}{1+\theta\left(\bar{N}_{t}\right) \omega}}\right]\left[\frac { \theta ( \overline { N } _ { t } ) } { \theta ( \overline { N } _ { t } ) - 1 } \left(\frac{1-\alpha \bar{q} g \bar{y} g \bar{b}^{\theta\left(\bar{N}_{t}\right)-1} \bar{\Pi}_{t}^{(1-\varrho)\left(\theta\left(\bar{N}_{t}\right)-1\right)}}{\left.\left.1-\alpha \bar{q} g \bar{y}_{\bar{b}} \theta\left(\bar{N}_{t}\right)-1 \bar{\Pi}_{t}^{(1-\varrho) \theta\left(\bar{N}_{t}\right)\left(1+\omega+\xi\left(\bar{N}_{t}\right)\right)}\right)\right] \ldots}\right.\right. \\
\ldots\left[\bar{D}_{t}^{\frac{-1}{(1-a)}} \bar{N}_{t}^{-\gamma\left(\bar{N}_{t}\right)(1+\omega)-\omega}\right]
\end{gathered}
$$

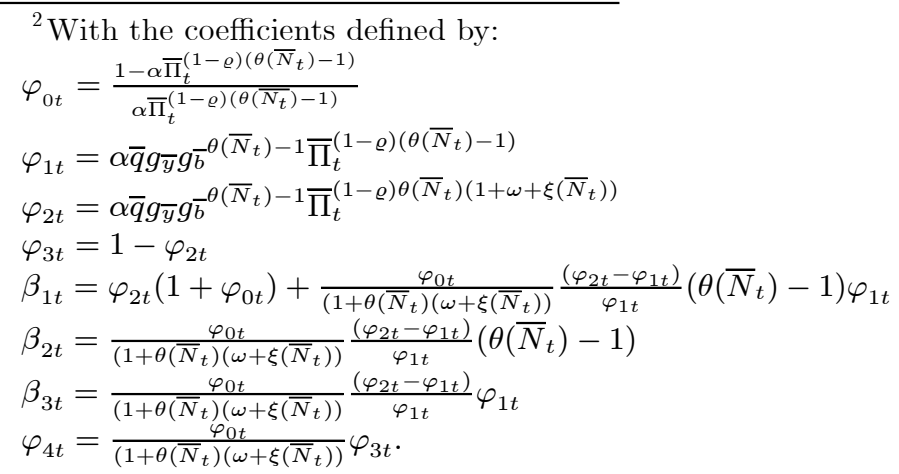


The long run restriction (3) is one of the five equations summarizing the steady state where number of firms $\bar{N}_{t}$, real average marginal cost $\overline{m c}_{t}$, aggregate output $\bar{Y}_{t}$, real wage $\left(\overline{\frac{W_{t}}{P_{t}}}\right)$ and relative price dispersion $\bar{D}_{t}$ are determined in function of trend inflation $\bar{\Pi}_{t}$ and trend costs of entry $\overline{f_{E}}$ (see appendix). Moreover, the target inflation rule (1) is added.

Hatted variables denote log deviation from trend values and a bar over a variable indicates its trend value. Thus, $\widehat{\pi}_{t}$ denotes $\log$ deviation of inflation from its trend value $\bar{\Pi}_{t}, \widehat{m c}_{t} \log$ deviation of average real marginal cost, $\widehat{N}_{t} \log$ deviation of the number of varieties ${ }^{3}$. The equation (2) differs from conventional versions of the NKPC in two respects. First, a number of additional variables appear on the right-hand side of (2). These include higher-order leads of expected inflation, innovations to trend inflation, terms involving the real discount factor and real output growth and also deviations of the number of varieties (instantaneous, lag and lead). Second, the coefficients of the variables are non linear functions of the trend values of the gross rate of inflation $\bar{\Pi}_{t}$ and of the number of varieties $\bar{N}_{t}$ and of structural parameters of the NK model, $\alpha$ the nominal price rigidity, $\varrho$ the backward partial indexation, $1-a$ the elasticity of the production relatively to labour, $\omega$ which measures the extent of strategic complementarity, and $\theta\left(\bar{N}_{t}\right), \xi\left(\bar{N}_{t}\right), \gamma\left(\bar{N}_{t}\right)$, respectively the elasticity of substitution, the elasticity of the mark-up and the consumer taste for variety at their steady state values.

First, in the long run, real average marginal cost decreases with inflation, but this effect is enhanced in an economy where the cost of entry for firms is low; real average marginal cost also increases with the number of varieties. Second, the increase of the slope with decreasing trend inflation can be alleviated, even inverted, by the decrease of the slope in the tendency of the number of varieties because of increasing elasticity of substititution of demand with the number of varieties, without referring to an increase in partial indexation or an endogenous price rigidity. The impact of expectations of inflation farther in the future is not only enhanced as trend inflation increases but also with the tendency of the number of varieties. Therefore, in a context of decreasing trend inflation, the coefficients of the NKPC can be stabilized through the increase of competitive pressures and that of the elasticity of the demand faced by the firms, both implied by an increase in the tendency in the number of varieties.

\subsection{A simplified version of the enlarged NKPC}

Omitting the fluctuations of the number of varieties around their steady state values and with a quite small coefficient $\beta_{3}$, we henceforth derive a simplified version of (2):

$$
\widehat{\pi}_{t}-\varrho \widehat{\pi}_{t-1}=\varphi_{4} \widehat{m c}_{t}+\beta_{1} E_{t}\left(\widehat{\pi}_{t+1}-\varrho \widehat{\pi}_{t}\right)+\beta_{2} E_{t} \sum_{j=2}^{\infty} \varphi_{1}^{j}\left(\widehat{\pi}_{t+j}-\varrho \widehat{\pi}_{t+j-1}\right)
$$

and its closed form solution:

$$
\widehat{\pi}_{t}=\varrho \widehat{\pi}_{t-1}+\varphi_{4} E_{t} \sum_{j=0}^{\infty} \beta_{1}^{j} \widehat{m c}_{t+j}+\beta_{2} E_{t} \sum_{k=0}^{\infty} \beta_{1}^{k} \sum_{j=2}^{\infty} \varphi_{1}^{j}\left(\widehat{\pi}_{t+k+j}-\varrho \widehat{\pi}_{t+k+j-1}\right)
$$

with the long run restriction (3) between $\bar{N}_{t}, \bar{\Pi}_{t}$ and $\overline{m c}_{t}$ and the target inflation rule (1).

\footnotetext{
${ }^{3}$ Specifically, $\widehat{\pi}_{t}=\ln \left(\Pi_{t} / \bar{\Pi}_{t}\right), \widehat{m c}_{t}=\ln \left(m c_{t} / \overline{m c}_{t}\right), \widehat{N}_{t}=\ln \left(N_{t} / \bar{N}_{t}\right), \quad \widehat{g}_{t}^{\pi}=\ln \left(\bar{\Pi}_{t} / \bar{\Pi}_{t-1}\right), \widehat{g}_{t}^{y}=\ln \left(g_{t}^{y} / \bar{g}^{y}\right)$, $\widehat{q}_{t, t+1}=\ln \left(q_{t, t+1} / \bar{q}_{t, t+1}\right)$ with $q_{t, t+1}$ the real discount factor between time $t$ and $t+1$.
} 
Henceforth, in a context of decreasing trend inflation but increasing number of varieties, we assume that the coefficients of this NKPC are constant.

\section{Econometric Approach}

\subsection{Characterizing inflation, growth of real GDP and product market regu- lation processes}

According to the literature on the "Great moderation" and on the "Inflation stabilization" (see Stock and Watson (2002, 2003, 2005, 2007), Cecchetti and al. (2007), Cogley and Sargent (2005), Cogley and Sbordone (2008), Cogley and al. (2008)), one can start with several postulates. (1) The inflation process in the G-7 countries can well be approximated as the sum of a persistent component and a transitory one. The persistent component captures the stochastic trend $\bar{\Pi}_{t}$ which evolves as a driftless random walk while the cyclical component represents temporary differences between actual and trend inflation. Because trend inflation is a driftless random walk, actual inflation has a unit autoregressive root and is highly persistent. (2) Moreover, variability of both the trend and temporary components is allowed to change over time. This time variation captures the fact that trend inflation has been relatively stable in the G-7 over the past decade, while trend inflation was much more variable in the 1970s (when it rose) and early 1980s (when it fell) in much of the G-7. (3) Real GDP growth rates in the G-7 are well characterized, at least locally, by low order autoregressive (AR) models where the AR coefficients are allowed to drift through time and the volatility of the process is time-varying.

Lastly, we assume that entry costs follow an exogenous nonstationary stochastic process. This assumption is consistent with the OECD product market regulation $\left(p m r_{t}\right)$ indicators characteristics which exhibit highly persistent underlying trend. Anglo-saxon countries, in particular the US, actually experienced large changes in the regulations of the product market since the end of 1970s. European countries, and France in particular, also experienced product market regulation changes, but those started only ten years later, from the late 1980s, and for France, at a higher speed than in the US. However, the level reached in the mid-2005 by France remains 2 points higher than the US'one (figures 1, 2, 3, and see appendix for data sources and methodology).

\section{Insert Figures 1, 2, 3}

\subsection{Empirical variants of the enlarged NKPC and $V A R$ expectations}

Following Sbordone (2002, 2005), Fanelli (2008) and Cogley and Sbordone (2008), we estimate different specifications deriving from the simplified version of the enlarged NKPC in its closed form solution (5) with the long run restriction (3) and the target inflation rule (1) by the two-step distance estimator based on Campbell and Shiller's procedure (1987). We describe the general principle of the method; then, we adapt it to both the properties of our processes and our models. 


\subsubsection{The method: estimation by the two-step procedure}

We assume that agents form expectations with a forecasting $V A R$. We use an auxiliary $V A R$ process, assuming a vector of forecasting variables $X_{t}(n, 1)$ including at least current gross inflation rate (in logarithm) and the labor share (in logarithm), with a $V A R(p)$ representation:

$$
X_{t}=A_{1} X_{t-1}+\ldots+A_{p} X_{t-p}+\left[B W_{t}\right]+u_{t}
$$

where $B$ is a $(n, k)$ matrix and $W_{t}$ is a vector $(k, 1)$ of exogenous variables. $W_{t}$ may be reduced to the constant variable.

The $V A R(p)$ representation can be rewritten as a $V A R(1)$, using the companion matrix $\Phi$ :

$$
Z_{t}=\Phi Z_{t-1}+\left[C W_{t}\right]+U_{t}
$$

where $Z_{t}=\left(X_{t}, X_{t-1}, \ldots, X_{t-p+1}\right)^{\prime} \quad(n . p, 1)$, and

$$
\Phi=\left(\begin{array}{cccc}
A_{1} & A_{2} & & A_{p} \\
I_{n} & 0 & & 0 \\
& & & \\
0 & 0 & I_{n} & 0
\end{array}\right) \quad(n . p, n . p), \text { with } C=(B, 0, \ldots, 0)^{\prime} \quad(n . p, k) \text { and } U_{t}=\left(u_{t}, 0, \ldots, 0\right)^{\prime}
$$

We write :

$\pi_{t}=e_{\pi}^{\prime} Z_{t}$ and $m c_{t}=e_{m c}^{\prime} Z_{t}$ with an appropriate definition of the selection vectors $e_{\pi}$ and $e_{m c}$.

We define the stochastic trend in $Z_{t}$ as the value to which the serie is expected to converge in the long run $\bar{Z}_{t}=\lim _{h \rightarrow \infty} E_{t} Z_{t+h}$. Here $\bar{Z}_{t}$ is defined by $\bar{Z}_{t}=(I-\Phi)^{-1}\left[C W_{t}\right]$ and thus $\widehat{Z}_{t}$ by $\widehat{Z}_{t}=Z_{t}-\bar{Z}_{t}$.

The reduced-form conditional expectation of $\widehat{\pi}_{t}$ is $E_{t}\left(\widehat{\pi}_{t} / \widehat{Z}_{t-1}\right)=e_{\pi}^{\prime} \Phi \widehat{Z}_{t-1}$.

Similarly, the infinite sum of expected future values of the labor share is computed as:

$$
\sum_{j=0}^{\infty} \beta_{1}^{j} E_{t} \widehat{m c}_{t+j}=e_{m c}^{\prime}\left(I-\beta_{1} \Phi\right)^{-1} \Phi \widehat{Z}_{t-1}
$$

and the infinite sum of expectations farther in the future can be written as:

$$
E_{t} \sum_{k=0}^{\infty} \beta_{1}^{k} \sum_{j=2}^{\infty} \varphi_{1}^{j}\left(\widehat{\pi}_{t+k+j}-\varrho \widehat{\pi}_{t+k+j-1}\right)=\left(I-\beta_{1} \Phi\right)^{-1}\left(e_{\pi}^{\prime}\left(\varphi_{1}^{2}\left(I-\varphi_{1} \Phi\right)^{-1}\left(\Phi^{3} \widehat{Z}_{t-1}-\varrho \Phi^{2} \widehat{Z}_{t-1}\right)\right)\right.
$$

Thus, the conditional expectation of $\widehat{\pi}_{t}$ in the model (5) is:

$$
\widehat{\pi}_{t}^{s} \equiv E_{t}\left(\widehat{\pi}_{t} / \widehat{Z}_{t-1}\right)=\varrho e_{\pi}^{\prime} \widehat{Z}_{t-1}+\varphi_{4} e_{m c}^{\prime}\left(\left(I-\beta_{1} \Phi\right)^{-1} \Phi \widehat{Z}_{t-1}\right)+\beta_{2}\left(\left(I-\beta_{1} \Phi\right)^{-1} e_{\pi}^{\prime} \varphi_{1}^{2}\left(I-\varphi_{1} \Phi\right)^{-1}\left(\Phi^{3} \widehat{Z}_{t-1}-\varrho \Phi^{2} \widehat{Z}_{t-1}\right)\right.
$$

The parameters to be estimated in the NKPC are $\psi=\left(\varrho, \varphi_{4}, \beta_{2}\right)$. 
After equating reduced-form and structural forecasts of the inflation gap $\widehat{\pi}_{t}$, we obtain a set of non-linear cross-equations restrictions involving the parameters $\psi$ of the model and the $V A R$ parameters $\Phi$ and $[C]$ :

$e_{\pi}^{\prime} \Phi-\varrho e_{\pi}^{\prime}+\varphi_{4} e_{m c}^{\prime}\left(\left(I-\beta_{1} \Phi\right)^{-1} \Phi\right)+\beta_{2}\left(\left(I-\beta_{1} \Phi\right)^{-1} e_{\pi}^{\prime} \varphi_{1}^{2}(I-\varphi \Phi)^{-1}\left(\Phi^{3}-\varrho \Phi^{2}\right)\right)=0$ or $F_{1}(\psi, \Phi,[C])=0$

The parameters must also satisfy the long run restriction (3) between $\overline{m c}_{t}, \bar{\Pi}_{t}$ and $\bar{N}_{t}$ and the target rule $(1)$ or $F_{2}(\psi, \Phi,[C])=0$.

Defining $F(\psi, \Phi,[C])$ by $\left(F_{1}, F_{2}\right)$, the minimum distance estimator $\widehat{\psi}$ of $\psi=\left(\varrho, \varphi_{4}, \beta_{2}\right)$ is defined as the vector that minimizes the square of the function $F(\psi, \widehat{\Phi},[\widehat{C}])$ for consistent estimates of $\Phi$ (and $[C]$ ) . The minimum distance estimator $\widehat{\psi}$ is then defined as $\widehat{\psi}=$ $\arg \min \left[F(\psi, \widehat{\Phi},[\widehat{C}])^{\prime} F(\psi, \widehat{\Phi},[\widehat{C}])\right]$.

The two-step procedure will be: 1) to estimate an auxiliary $V A R$ and consistent estimates of $\Phi$ (and $[C]) ; 2)$ to estimate the parameters $\psi=\left(\varrho, \varphi_{4}, \beta_{2}\right)$ of the model through a minimum distance procedure.

\subsubsection{Application of the two-step procedure}

We apply the two-step procedure to the estimation of three specifications, with two variants $\mathrm{V}$ and $\mathrm{V}$ ' for each one, deriving from the closed form solution (5):

Variant V: $\widehat{\pi}_{t}=\varrho \widehat{\pi}_{t-1}+\varphi_{4} E_{t} \sum_{j=0}^{\infty} \beta_{1}^{j} \widehat{m c}_{t+j}$

Variant V': $\widehat{\pi}_{t}=\varrho \widehat{\pi}_{t-1}+\varphi_{4} E_{t} \sum_{j=0}^{\infty} \beta_{1}^{j} \widehat{m c}_{t+j}+\beta_{2} E_{t} \sum_{k=0}^{\infty} \beta_{1}^{k} \sum_{j=2}^{\infty} \varphi_{1}^{j}\left(\widehat{\pi}_{t+k+j}-\varrho \widehat{\pi}_{t+k+j-1}\right)$

The variant V' includes the additional variable for the expectation in the future of inflation and thus assumes of a non zero trend inflation. The variant $\mathrm{V}$ omits the expectation in the future of inflation (the coefficient $\beta_{2}$ becomes null) and corresponds to a simplified version of V'; in case of zero trend inflation it corresponds to the usual hybrid NKPC with no time-varying trend inflation.

We estimate a trivariate auxiliary $V A R$ of the form $X_{t}=\left(\ln \left(m c_{t}\right), \ln \left(\Pi_{t}\right), g_{y_{t}}\right)^{\prime}$, with $m c_{t}$ proxied by the labor share, $\Pi_{t}$ is the gross inflation rate (corrected in the model 3 from its trend through a cointegrating relation) and $g_{y_{t}}$ the growth of real GDP. The three models diverge in the way the product market regulation $p m r_{t}$ is introduced as exogenous variable in the VAR.

In the model 1 the $V A R$ only includes the constant as exogenous variable. The variant V1 corresponds to the usual hybrid NKPC with no time-varying trend inflation and no timevarying number of varieties (in this case, $\beta_{1}$ is assumed to be equal to 0.99 ). The variant V1' corresponds to an approximated hybrid NKPC with time-varying trend inflation as in Cogley and Sbordorne (2008), but where the coefficients of the VAR are assumed to be constant and the variables in the NKPC are not taken in deviation of their trend.

In the model 2 the $V A R$ also includes the product market regulation variable as exogenous variable. The variant V2' corresponds to the hybrid NKPC incorporating both time-varying trend inflation and time-varying number of varieties. Following numerical calculations, in an environment of decreasing inflation trend and increasing trend in the number of varieties, we 
assume that the coefficients $\beta_{1}$ and $\varphi_{1}$ are constant and respectively equal to 1.01 and 0.78 ; we also assume $\varphi_{4}$ and $\beta_{2}$ to be constant. The variant V2 corresponds to a simplified version of $\mathrm{V} 2$ '.

In the model 3 the $V A R$ doesn't include the product market regulation as exogenous variable, because the inflation has already been corrected from its stochastic trend through its cointegrating relation with the product market regulation. It corresponds to a restricted version of the model 2 or to a specific version of the model 1 where the variable of inflation $\ln \left(\Pi_{t}\right)$ is replaced by its deviation from the monetary inflation target $\ln \left(\Pi_{t} / \bar{\Pi}_{t}\right)$.

\subsubsection{Empirical results}

The $V A R$ lag length, 5, has been selected by combining standard information criteria (Akaike, Schwarz, Hannan-Quinn) with residual-based diagnostic tests. In each $V A R$, the innovations for inflation and growth real GDP in the US and in France present stochastic volatilities in accordance with the literature (see 3.1). We modelize it with a $\operatorname{Garch}(1,1)$, where the representation of the conditional variance of the residuals $\varepsilon_{t}$ is expressed as: $\sigma_{t}^{2}=a_{0}+a_{1} \sigma_{t-1}^{2}+a_{2} \varepsilon_{t-1}^{2}$.

For each model, in both countries, we test the assumption of constant coefficients of the VAR through the conditional variance of the residuals specification allowing for the inclusion of the predetermined regressor $\exp \left(p m r_{t}\right)$. This inclusion is always rejected.

The non-linear long run restriction (3) between $\overline{m c}_{t}, \bar{\Pi}_{t}$ and $\bar{N}_{t}$ is obviously rejected by the data in the US and France because the period of estimation exhibits downward trend in the product market regulation, in inflation and in real marginal costs. However, both for the US and France, the inflation target rule (1) cannot be rejected at the standard confidence levels: the impact of product market regulation on inflation is greater (multipled by 4.5) in long run for the US than for France.

In the tables of results (see tables 1 and 2$) \ln (\Pi)^{p}$ indicates the inflation series predicted (static forecasting) by the model, and two statistics measure the approximation of predicted to actual inflation: the ratio of the standard deviations, $\sigma_{\ln (\Pi)^{p}} / \sigma_{\ln (\Pi)}$, and the correlation coefficient, $\operatorname{corr}\left(\ln (\Pi)^{p}, \ln (\Pi)\right)^{4}$.

For the model 1, in our first step procedure we estimate the baseline unrestricted auxiliary $V A R$. For the US, the estimated $V A R$ exhibits no serial correlation of the residuals (only at $\mathrm{p}=10 \%$ for the growth of real GDP) in spite of close to unit roots. This result suggests the existence of long term relations between the non-stationary variables. Thus, for the US, the least square estimates of the VAR are consistent. Moreover, the hypothesis that inflation has no predictive power for the labor share can be rejected at the confidence level $\mathrm{p}=0.15$; the one that labor share has no predicive power for inflation can be rejected at the standard confidence levels. For France, the hypothesis that inflation and growth of real GDP have no predictive power for the labor share cannot be rejected at standard confidence level; the one that inflation has no predictive power for the growth of real GDP cannot also be rejected at standard confidence level. Furthermore, we obtain serial correlated residuals in the equations of labor share and inflation in

\footnotetext{
${ }^{4}$ We should take into account the uncertainty associated with the first step estimate of the $V A R$ parameters, using bootstrap procedure.
} 
the $V A R$ with roots of the $V A R$ close to the unit circle. In that case, the least square estimates of the $V A R, \widehat{\Phi}$ and $[\widehat{C}]$, are not consistent.

Using the two step procedure different results emerge: in the model V1, the indexation parameter $\varrho$ estimate is rather high ( 0.59 for both the US and France). The correlation between the sum of expected value of real marginal costs and inflation is rather high for the US and France (resp. 0.81 and 0.86).

The introduction of the expectations of inflation further in the future as additional variable in the second step (model V1') reduces the estimate of $\varrho$ (from 0.59 to 0.49 for the US and from 0.59 to 0.36 for France) and slightly reduces the estimate of the slope: in the US, from 0.0108 to 0.0086 , and in France from 0.0142 to 0.0133 . It seems that the variable of the expectations of inflation further in the future (very well correlated with inflation, 0.84 in the US and 0.83 in France) takes a part of the inflation persistence otherwise taken by the lagged variable $\widehat{\pi}_{t-1}$. For the US, although the least square estimates of the coefficients of the VAR are consistent, the models V1 and V1' appear to be poorly specified because of the omission of trend variables.

These results confirm the poor empirical performance of the standard NKPC or of the NKPC with time-varying trend inflation, but assuming constant coefficients in the VAR.

For the model 2, the unrestricted auxiliary $V A R$ includes an additional exogenous variable, the product market regulation variable $p m r_{t}$ (in exponential) which presents a persistent underlying decreasing trend. The product market regulation variable seems to capture a part of the persistence of endogenous variables in the US but not in France. The serial correlation of estimated residuals in the $V A R$ is rejected at the standard confidence level for the US. The highest modulus of the root becomes 0.87 for the US. Moreover, both the hypotheses that inflation has no predictive power for the labor share and that labor share has no predictive power for inflation can be rejected at standard confidence levels. Further, the hypothesis that inflation has no predictive power for growth of real GDP can be rejected for the US. For France, serial correlation of residuals for labor share and inflation equations does not disappear and the highest modulus of roots remains high, 0.92 . The hypothesis that inflation has no predictive power for the labor share and the one that inflation has no predictive power for growth of real GDP cannot be rejected at standard confidence levels.

We apply the two step procedure and find a better performance of the model V2 in comparison with the model V1, at least in the US. The estimate of the indexation parameter $\varrho$ is reduced ( 0.38 for the US, 0.340 for France) in comparaison with the model V1 (0.59 for both the US and France). The estimate of the slope is slightly reduced (to 0.0082 in the US and 0.0070 in France). The correlation between the sum of the expected value of fluctuations of real marginal costs and deviation of inflation around its trend is now rather small for the US and very high for France (resp. 0.33 and 0.97).

The introduction of the expectations of inflation further in the future as additional variable in the second step (model V2') doesn't change the estimates of $\varrho$ (at 0.380 ) and of the slope in the US. On the contrary, it reduces the estimation of $\varrho$ and increases the one of the slope in France. Finally, the model V2 presents a better performance than the model V1 for the US. Moreover, the introduction of the expectations of inflation further in the future doesn' improve performances of the model 2 .

We then estimate the model 3 explicitly taking into account a long term relation between inflation and product market regulation (model 3). Both for the US and France we exhibit 
a cointegrating relation between inflation and product market regulation, but in the US the influence of product market regulation is 4.5 times the one in France. The variable $\ln \left(\Pi_{t}\right)$ is, from now on, corrected from its cointegrating relation. Estimated residuals in the $V A R$ exhibit no more any serial correlation for both countries. For the US, the hypothesis that the corrected inflation variable has no predictive power for the labor share cannot be rejected at $\mathrm{p}=0.12$ and that labor share has no predictive power for the inflation corrected for its trend cannot be rejected at $p=0.20$. For France, the hypotheses that the corrected inflation variable has no predictive power for the labor share and for growth real of GDP cannot be rejected at the standard confidence levels.

In the model V3, the estimate of the indexation parameter $\varrho$ is approximately equal to the model V2's for the US (0.36), or weaker for France (0.28 instead of 0.340). The estimate of the slope is a little larger than in the model V2 and close to the model V1 (0.0102) in the US and is a little larger in France (0.0183 instead of 0.0142). In the model V3', the estimates of the indexation parameter and of the slope are very close to those in the model 3 . The estimate of the coefficient of the additional variable appears negative (-0.0068). For France, the estimate of the indexation parameter is weaker $(0.21)$ whereas the estimate of the slope is rather high (resp. $0.0205)$.

These results point out that the model V3 (or V3'), which is a restricted version of the model V2 (or V2'), does not improve the empirical adequation for the US in comparison with the model V2 (or V2'). However, it does in France in comparison with the model V2 (or V2').

Finally, the main findings of this empirical investigation are the following: (1) the introduction of the product market regulation variable highly improves the adequation of the new Keynesian Phillips curve to the data and seems to correct misspecification due to the omission of a variable; (2) the introduction of the product market regulation variable matches a part of the observed persistence in inflation; it is a good candidate to account for the time-varying trend of inflation; it also lowers the estimate of the partial indexation and so of the backward-looking component of inflation; (3) the long run restriction (3) between $\overline{m c}_{t}, \bar{\Pi}_{t}$ and $\bar{N}_{t}$ is rejected by the data, both in the US and in France; (4) the target inflation rule (1) linking inflation and product market regulation in the long run cannot be rejected at the standard levels: the impact of product market regulation on inflation is 4.5 times greater in long run for the US than for France; (5) in all cases, the estimate of the slope of the Phillips curves remains rather small; (6) the introduction of the additional variable of expectations of inflation further in the future seems to be necessary to take a part of the observed inflation persistence only when the product market variable is absent of the specifications.

\section{insert Tables 1,2: Parameter estimates and moments (US and France)}

\section{Conclusion}

In this paper, we investigate the impact of product market regulation on inflation dynamics. We use an enlarged theoretical version of the NKPC incorporating entry of firms and increasing competitive pressures in the number of firms in an environment of time-varying trend inflation and time-varying trend in number of varieties. In a context of decreasing trend inflation, the coefficients of the NKPC can be stabilized through the increase of competitive pressures and of 
the elasticity of the demand faced by the firms; both are implied by an increase in the tendency in the number of varieties.

We assess the empirical relevance of different specifications of this NKPC for inflation dynamics, assuming expectations formed with a $V A R$ with constant coefficients. We restrict the empirical evidence to the US and France. In the first country, changes in the regulation of product market regulation have mainly been achieved; in the second one, they are still in progress. We use OECD indicators on product market regulation, characterized by high persistence coming from their underlying trend and we give special emphasis to the non-stationary properties of the inflation process in the US and in France. The econometric results show that the introduction of the product market regulation variable highly improves the adequation of the $V A R$ and, at the same time, the one of the enlarged new Keynesian Phillips curve to the data. The data show a linear combination between the trend in inflation and the trend in the product market regulation: the estimate of the long run impact of product market regulation on inflation is more than 4 times higher in the US than in France. Further, the introduction of this variable lowers the estimate of the partial indexation. Finally, the product market regulation variable is a good candidate to be an exogenous structural source of the observed persistence in inflation during the last thirty years for both the US and France.

We provide an extension to the literature that already takes into account the slow moving trend in inflation in the derivation of the Calvo model: whereas, in much of this literature, the stochastic trend inflation is treated as an exogenous random process, in this paper, the link between the stochastic trend in inflation and the exogenous product market regulation process is induced by the target inflation rule. However, our analysis could be improved in a number of ways. The robustness of our results to alternative assumptions on the VAR coefficients and to alternative measures of processes governing the entry of firms should be further assessed. Finally, future empirical research should go on focusing on the origins of shifts in trend inflation. 


\section{P roduct market regulation}

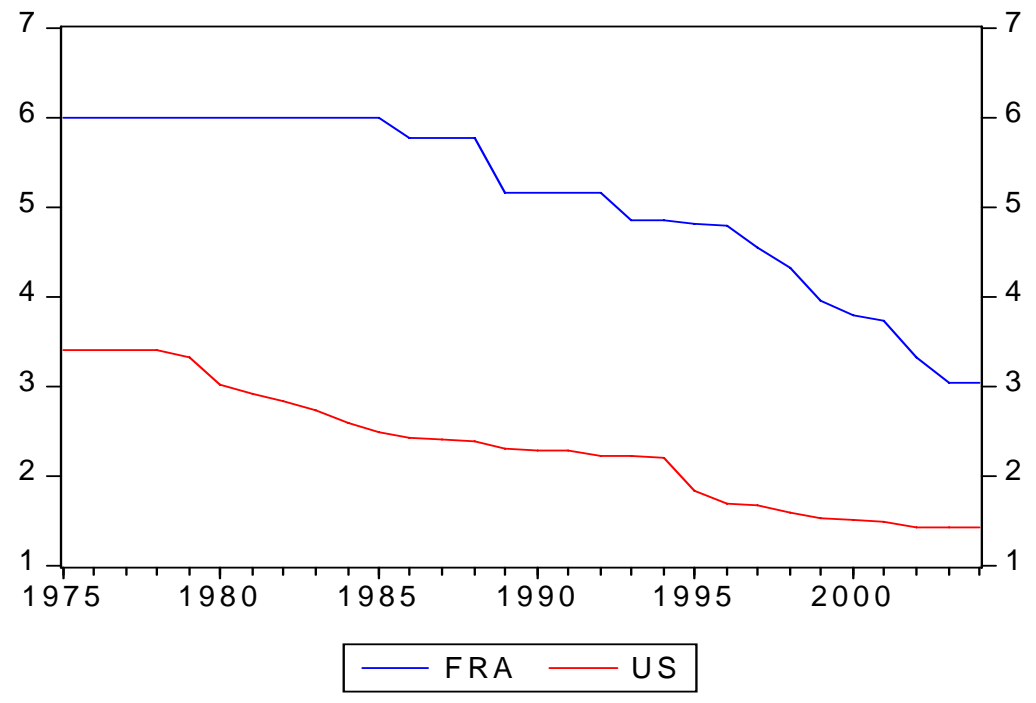

Figure 1:

Figure 1 


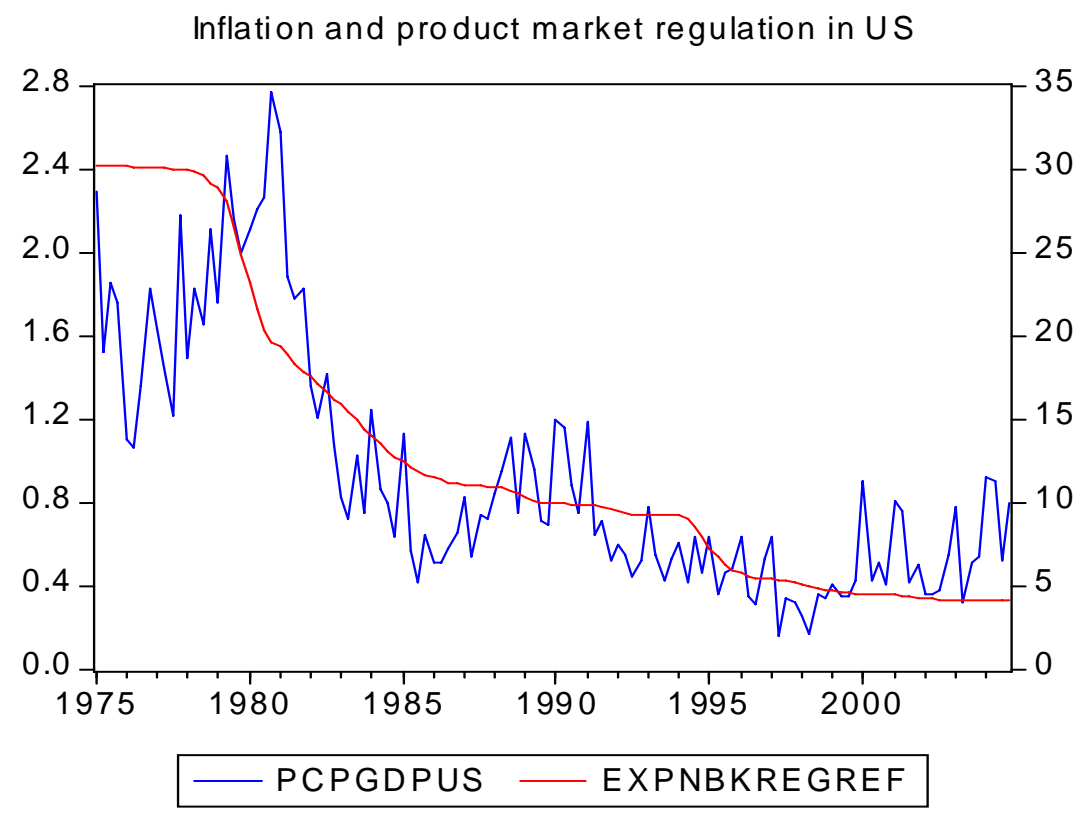

Figure 2:

Figure 2 


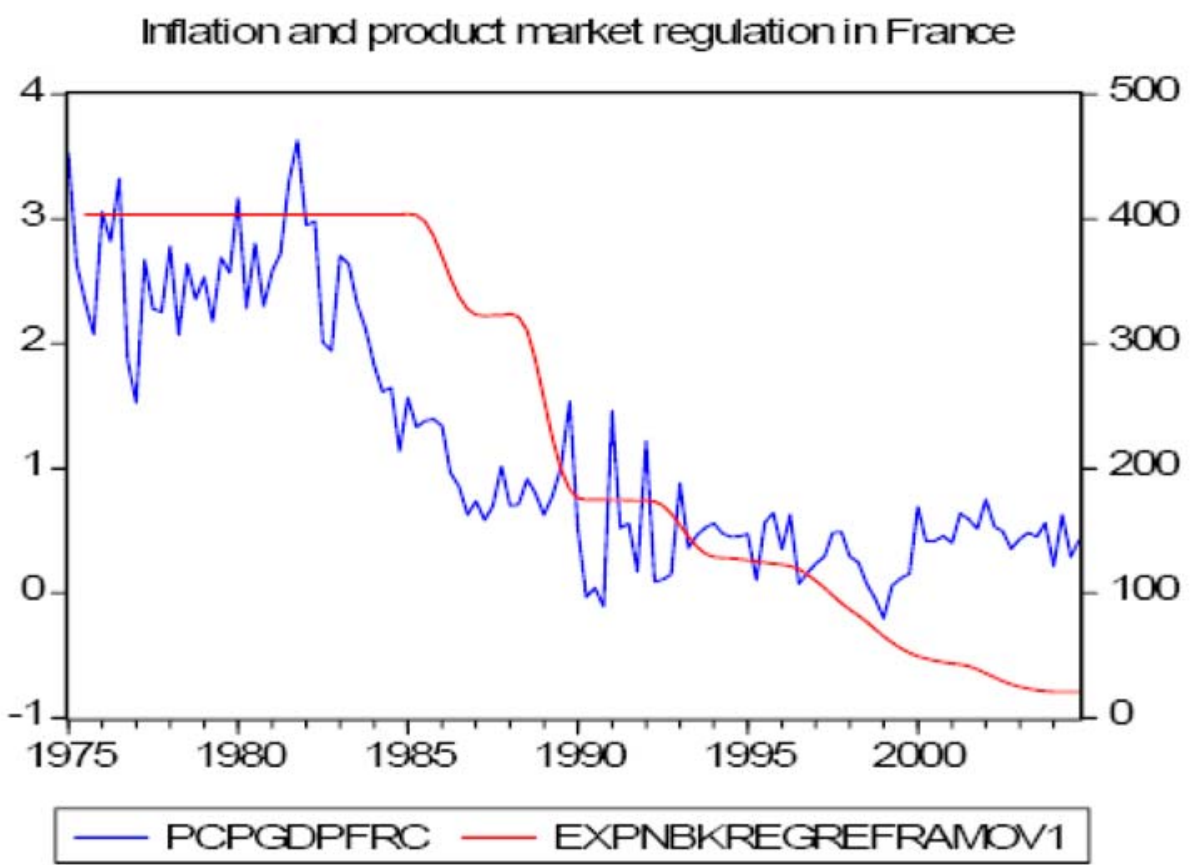

Figure 3:

Figure 3 


\section{Model 1}

$$
\varrho \quad \varphi_{4} \quad \beta_{2} \quad \operatorname{corr}\left(\ln (\Pi)^{p}, \ln (\Pi)\right) \quad \frac{\sigma_{\ln (\Pi) p}}{\sigma_{\ln (\Pi)}}
$$

Modulus of the highest root

of the $\operatorname{VAR}(5): 0.963$

$\mathrm{V} 1$

V1'

\section{Model 2}

Modulus of the highest root of the $\operatorname{VAR}(5): 0.867$

$$
\mathrm{V} 2
$$

$\mathrm{V} 2$
0.591

$$
0.591
$$$$
\text { (0.008) }
$$$$
0.490
$$

0.0108

0.90

0.91

0.490

$(0.002)$

0.0086

0.0070

0.90

0.91

(0.003) (0.007)
$0.377 \quad 0.0082$

$(0.074) \quad(0.004)$
$0.380)$

$0.380 \quad 0.0079$

(0.003)
0.87

0.82

0.82

\section{Model 3}

Estimated cointegrating relation:

$\ln \left(\Pi_{t}\right)=0.001927+0.000243 . \exp \left(p m r_{t}\right)$

Modulus of the highest root

of the $\operatorname{VAR}(5): 0.884$

$\mathrm{V} 3$

V3'
0.359

0.0103

0.91

0.90

\begin{tabular}{ll}
$(0.101) \quad(0.002)$ \\
\hline
\end{tabular}

0.355

0.90
0.0141

0.87

$$
(0.002) \quad(0.009)
$$

Sample: 1975Q1-2004Q4, 120 obs. (Models 1,1', 2, 2'); 1976Q2-2004Q4, 115 obs.(Models 3, 3')

Standard errors in parentheses

Table 1: Parameter estimates and moments (US) 


\section{Model 1}

$$
\varrho \quad \varphi_{4} \quad \beta_{2} \quad \operatorname{corr}\left(\ln (\Pi)^{p}, \ln (\Pi)\right) \quad \frac{\sigma_{\ln (\Pi) p}}{\sigma_{\ln (\Pi)}}
$$

Modulus of the highest root

of the $\operatorname{VAR}(5): 0.968$

$\mathrm{V} 1$

V1'

\section{Model 2}

Modulus of the highest root of the $\operatorname{VAR}(5): 0.924$

$\mathrm{V} 2$

V2'

$\begin{array}{llll}0.595 & 0.0142 & & 0.92 \\ (0.079) & (0.0033) & & \\ 0.360 & 0.0133 & 0.0024 & 0.91 \\ & (0.002) & (0.002) & \end{array}$

$\begin{array}{llll}0.340 & 0.0070 & & 0.98 \\ (0.121) & (0.001) & & \\ 0.180 & 0.0138 & -0.0094 & 0.93 \\ & (0.001) & (0.002) & \end{array}$

\section{Model 3}

Estimated cointegrating relation: $\ln \left(\Pi_{t}\right)=0.003273+5.37 .10^{-5} \cdot \exp \left(p m r_{t}\right)$ Modulus of the highest root of the $\operatorname{VAR}(5): 0.931$

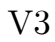

V3'

$\begin{array}{llll}0.280 & 0.190 & & 0.93 \\ (0.105) & (0.004) & & \\ 0.210 & 0.0205 & 0.0013 & 0.93 \\ & (0.002) & (0.005) & \end{array}$

Sample: 1975Q1-2004Q4, 120 obs. (Models 1,1', 2, 2'); 1976Q2-2004Q4, 115 obs.(Models 3, 3') Standard errors in parentheses

Table 2: Parameter estimates and moments (France) 


\section{$5 \quad$ References}

Ascari Guido (2004): "Staggered Prices and Trend Inflation: some Nuisances", Review of Economic Dynamics 7, 642-667.

Bakhshi, Hasan, Hashmat Khan, Pablo Burriel-Llombart, and Barbara Rudolf (2007): "The New Keynesian Phillips Curve Under Trend Inflation and Strategic Complementarity", Journal of Macroeconomics 29, 37-59.

Ball, Laurence (2000): "Near-Rationality and Inflation in Two Monetary Regimes", NBER Working Paper $n^{\circ} 7988$.

Ball, Laurence (2006): "Has Globalization Changed Inflation? ", NBER Working Paper $n^{\circ} 12687$.

Batini, Nicoletta, Brian Kackson, and Stephen Nickell (2005): "An Open-Economy New Keynesian Phillips Curve for the UK", Journal of Monetary Economics 52, 1061-1071.

Bilbiie, Florin O., Fabio Ghironi, and Marc J. Melitz (2007): "Monetary Policy and Business Cycles with Endogenous Entry and Product Variety", NBER, Working Paper n ${ }^{\circ} 13199$.

Bloch, Laurence (2009): "The New Keynesian Phillips Curve with Non Zero Steady State Inflation and Entry of Firms", Working Paper n²009-03, CREST-INSEE.

Borio, Claudio E.V, and Andrew J. Filardo (2007): "New Cross-Country Evidence on the Global Determinants of Domestic Inflation", BIS Working Paper.

Calvo, Guillermo (1983): " Staggered Prices in a Utility-Maximizing Framework", Journal of Monetary Economics 12 (3), 383-398.

Campbell, John Y., and Robert J. Shiller (1987): "Cointegration and Tests of Present Value Models", Journal of Political Economy 95, 1062-1088.

Cecchetti Stephen G., Peter Hooper, Bruce C. Kasman, Kermit L. Schoenholtz and Mark W. Watson (2007): "Understanding the Evolving Inflation Process", Report prepared for the US Monetary Policy Forum 2007.

Christiano, Lawrence J., Martin Eichenbaum, and Charles L. Evans (2005): "Nominal Rigidities and the Dynamic Effects of a Shock to Monetary Policy", Journal of Political Economy 113(1), 1-45.

Cogley, Timothy, and Thomas J. Sargent (2005): "Drifts and Volatilities: Monetary Policies and Outcomes in the WWU US", Review of Economics Dynamics 8, 262-302.

Cogley, Timothy, and Argia M. Sbordone (2008): "Trend Inflation, Indexation, and Inflation Persistence in the New Keynesian Phillips Curve", American Economic Review 98(5), 2101-2126.

Cogley, Timothy, Giorgio E. Primiceri, and Thomas J. Sargent (2008): "Inflation-Gap Persistence in the US", Working Paper, November.

Fanelli, Luca (2008): "Testing the New Keynesian Phillips Curve Through Vector Autoregressive Models: Results from the Euro Area", Oxford Bulletin of Economics and Statistics 70(1), 53-66.

Fuhrer, Jeff, and George Moore (1995): "Inflation Persistence", Quarterly Journal of Economics 110(1), 127-159.

Gali, Jordi, and Mark Gertler (1999): "Inflation Dynamics: a Structural Econometric Analysis", Journal of Monetary Economics 44(2), 195-222.

Ihrig, J., S.B Kamin, D. Lindner, and J. Marquez (2007): "Some Simple Tests of the Globalization and Inflation Hypothesis", Board of Governors, International Discussion Paper $\mathrm{n}^{\circ} 893$.

Ireland, Peter N. (2007): "Changes in the Federal Reserve's Inflation Target: Causes and Consequences", Journal of Money, Credit and Banking 39(8), 1851-82. 
King, Robert G., and Alexander L. Wolman (1996): "Inflation Targeting in a St. Louis Model of the 21st Century", Federal Reserve Bank of St. Louis Review, May-June 1996.

Kozicki, Sharon, and Peter A. Tinsley (2002): "Alternatives Sources of the Lag Dynamics", in Proceedings of the 2002 Bank of Canada Conference Adjustment and Monetary Policy.

Milani, Fabio (2007): "Expectations, Learning and Macroeconomic Persistence", Journal of Monetary Economics 54, 2065-2082.

Mishkin, Frederic S. (2007): "Inflation Dynamics", International Finance, Vol.10, n 3 (2007), pp.317-334.

Mishkin, Frederic S. (2008): "Globalization, Macroeconomic Performance, and Monetary Policy", NBER Working Paper n 13948.

Nicoletti, Giuseppe, and Stefano Scarpetta (2005): "Product Market Reforms and Employment in OECD Countries", OECD Economics Department Working Paper n 472.

Primiceri, Giorgio E. (2006), "Why Inflation Rose and Fell: Policy Makers'Beliefs and US Postwar Stabilization Policy", Quarterly Journal of Economics, 121(3), 867-901.

Roberts, John M. (1997): "Is Inflation Sticky", Journal of Monetary Economics 39, 173-196.

Roberts, John M. (2006): "Monetary Policy and Inflation Dynamics", International Journal of Central Banking, vol.2 (September), 193-230.

Sahuc Jean-Guillaume (2006): "Partial Indexation, Trend Inflation, and the Hybrid Phillips Curve", Economic Letters 90, 42-50.

Sargent, Thomas (1999): The Conquest of American Inflation, Princeton University Press, Princeton.

Sargent, Thomas, Noah Williams, and Tao Zha (2006), "Shocks and Government Beliefs: the Rise and Fall of American Inflation", American Economic Review 96(4), 1193-1224.

Sbordone, Argia M. (2002): "Prices and Unit Labor Costs: a New Test of Stickiness", Journal of Monetary Economics 49(2), 265-292.

Sbordone, Argia M. (2005): "Do Expected Future Marginal Costs Drive Inflatin Dynamics", Journal of Monetary Economics 52, 1183-1197.

Sbordone, Argia M. (2008): "Globalization and Inflation Dynamics: The Impact of Increased Competition", Federal Reserve Bank of New York Staff Report, n³24.

Schorfheide, Frank (2005): "Learning and Monetary Policy Shifts", Review of Economic Dynamics 8, 392-419.

Sims, Christopher A. and Tao Zha (2006): "Were There Regime Stwiches in U.S. Monetary Policy?", American Economic Review, 96(1), 54-81.

Stock, James H. and Mark W. Watson (2002): "Has the Business Cycle Changed and Why? ", NBER Macroeconomics Annual 2002.

Stock, James H. and Mark W. Watson (2003): "Has the Business Cycle Changed? Evidence and Explanations", in Monetary Policy and Uncertainty: Adapting to a Changing Economy, Federal Reserve Bank of Kansas City Jackson Hole Symposium.

Stock, James H. and Mark W. Watson (2005): "Understanding Changes In International Business Cycle Dynamics", Journal of the European Economic Association 3(5), 968-1006.

Stock, James H. and Mark W. Watson (2007): "Why has US Inflation Become Harder to Forecast", Journal of Money, Credit and Banking, Supplement to Vol.39, n¹. 


\section{Appendix}

\subsection{Steady State under Exogenous Positive Trend Inflation and Sunk Entry Costs}

In this enlarged NK model, the steady state is summarized through five equations which determine the steady state number of firms $\bar{N}$, real average marginal cost $\overline{m c}$, aggregate output $\bar{Y}$, real wage $\frac{\bar{W}}{\bar{P}}$ and relative price dispersion $\bar{D}$ in function of steady state inflation $\bar{\Pi}$, sunk entry costs $\overline{f_{E}}$, productivity $\bar{A}$ and labor subsidy rate $\bar{\tau}$ and structural parameters of the NK model, $\beta$ the subjective discount factor, $\alpha$ the nominal price rigidity, $\varrho$ the backward partial indexation, $1-a$ the elasticity of the production relatively to labour, $\omega$ which measures the extent of strategic complementarity, $\delta$ the proportion of exit per period among the firms and $\theta(\bar{N}), \xi(\bar{N}), \gamma(\bar{N})$, respectively the elasticity of substitution, the elasticity of the mark-up and the consumer taste for variety at their steady state values (see Bloch (2009) for more details).

The first one is mainly induced by the aggregate free entry condition:

$$
\overline{m c}=\frac{1}{1-a}\left(1-\frac{\bar{W}}{\bar{P}} \frac{\overline{f_{E}}}{\bar{A}}(1-\beta(1-\delta)) \frac{\bar{N}}{\bar{Y}}\right)
$$

The second equation is the steady state expression of the economy's average marginal markup:

$$
\begin{gathered}
(1 / \overline{m c})=\left[\left(\frac{1-\alpha \bar{\Pi}^{(1-\varrho)(\theta(\bar{N})-1)}}{1-\alpha}\right)^{\frac{1-\theta(\bar{N})}{1+\theta(\bar{N}) \omega}}\right]\left[\frac { \theta ( \overline { N } ) } { \theta ( \overline { N } ) - 1 } \left(\frac{1-\alpha \bar{q} g_{\bar{y}} g^{-\theta-1} \bar{\Pi}^{(1-\varrho)(\theta(\bar{N})-1)}}{\left.\left.1-\alpha \bar{q} g \bar{y}_{\bar{b}} \bar{b}^{\theta-1} \bar{\Pi}^{(1-\varrho) \theta(\bar{N})(1+\omega+\xi(\bar{N}))}\right)\right] \ldots}\right.\right. \\
\ldots\left[\bar{D}^{\frac{-1}{(1-a)}} N^{-\gamma(\bar{N})(1+\omega)-\omega}\right]
\end{gathered}
$$

The thirth and fourth ones are derived from labor supply and market clearing in labor market:

$$
\overline{m c}=\frac{\chi}{(1-a)(1+\bar{\tau})}\left[\left(\frac{\overline{Y D}}{\bar{A}}\right)^{1 /(1-a)}+\overline{N_{E}} \frac{\overline{f_{E}}}{\bar{A}}\right]^{\varphi}\left(\frac{\overline{Y D}}{\bar{A}}\right)^{1 /(1-a)}
$$

with $\overline{N_{E}}=\frac{\delta}{(1-\delta)} \bar{N}$.

$$
\frac{\bar{W}}{\bar{P}}=\overline{m c}(1-a) \frac{\bar{Y}}{\left(\frac{\overline{Y D}}{\bar{A}}\right)^{1 /(1-a)}}
$$

The last equation is the expression of the relative price dispersion in the steady state:

$$
\bar{D}=\bar{N}^{-(\gamma(\bar{N})+a)}\left(\frac{1-\alpha}{1-\alpha \bar{\Pi}^{(1-\varrho) \frac{\theta(\bar{N})}{1-a}}}\right)^{1-a}\left(\frac{1-\alpha \bar{\Pi}^{(1-\varrho)(\theta(\bar{N})-1)}}{1-\alpha}\right)^{\frac{\theta(\bar{N})}{(\theta(\bar{N})-1)}}
$$




\subsection{Data Sources and Methodology}

\section{Product market regulation}

OECD summary indicator of regulatory impediments to product market competition in seven non- manufacturing industries (Nicoletti and Scarpetta (2005)). The data covers regulations and market conditions in seven non-manufacturing industries: gas, electricity, post, telecommunications, passenger air transport and road freight. Detailed qualitative and quantitative data on several dimensions are aggregated and coded into synthetic indicators that are increasing in the degree of restrictions to private ownership and competition. Dimensions covered are degree of public ownership, legal impediments to competition, degree of vertical integration of natural monopoly and competitive activites in network industries, market share of incumbent or new entrants in network industries, price controls in competitive activities. The data are yearly over the 1975-2004 period. Source: OECD.

These annual data are converted in quarterly data by match average and are band-pass filtered through [2, 8 quarters]. 